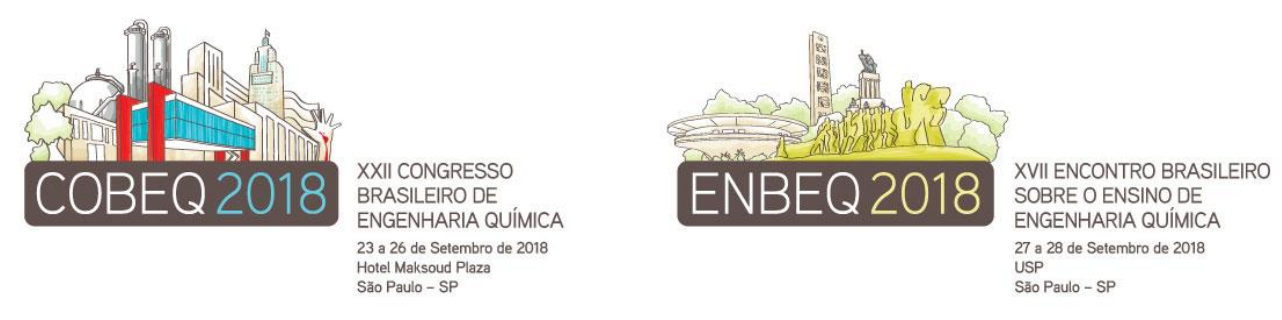

\title{
ESTUDO DE DIFERENTES ESTRATÉGIAS DE GRANULAÇÃO DE LODO ANAERÓBIO E O EFEITO DE MICROPOLUENTES EM SUA ESTABILIDADE
}

\author{
FARIA CV ${ }^{1}$, SOUZA DF ${ }^{2}$, PONTES TM², DUTRA HAR ${ }^{2}$, MORAVIA MCSA ${ }^{3}$, FONSECA, \\ $\mathrm{FV}^{1}$. \\ ${ }^{1}$ Universidade Federal do Rio de Janeiro, Escola de Química, Departamento de Processos \\ Inorgânicos \\ ${ }^{2}$ Pontifícia Universidade Católica de Minas Gerais, Departamento de Engenharia Química \\ ${ }^{3}$ Universidade Federal de Minas Gerais, Escola de Engenharia, Departamento de Engenharia \\ Sanitária e Ambiental \\ E-mail para contato: claraquimicaindustrial@gmail.com
}

\begin{abstract}
RESUMO - O lodo granular pode ser mais adequado quando comparado ao lodo floculento para algumas configurações de reatores anaeróbios, devido ao seu maior desempenho de sedimentação e maior capacidade de filtração. Existem estudos demonstrando o uso de cátions polivalentes e salinidade para a granulação de lodo. No presente trabalho, um estudo comparativo foi realizado com a aplicação de dois compostos diferentes para a granulação: cloreto de sódio $(\mathrm{NaCl})$ e cloreto de cálcio $\left(\mathrm{CaCl}_{2}\right)$. Foram utilizados três reatores anaeróbios em batelada sequencial com $1 \mathrm{~L}$, sendo alimentados em ciclos de 8 e 16 horas. Todos os reatores foram alimentados com esgoto sanitário sintético: $R 1$ foi o reator controle, $R 2$ foi alimentado com excesso de $\mathrm{NaCl}$ e R3 com excesso de $\mathrm{CaCl}_{2}$. Os resultados mostraram uma maior eficiência na granulação de lodo anaeróbio utilizando excesso de $\mathrm{CaCl}_{2}$. Outros testes vêm sendo realizados para avaliar o efeito da adição contínua ou intermitente do $\mathrm{CaCl}_{2}$ na granulação do lodo e além disso busca-se avaliar também os efeitos da adição de micropoluentes (fármacos) na estabilidade do lodo.
\end{abstract}

\section{INTRODUÇÃO}

Há descrições na literatura de reatores anaeróbios que priorizam o uso de biomassa granular, como por exemplo: reator de leito granular expandido (EGSB), algumas configurações de reatores anaeróbios operados em batelada sequencial (ASBR) e até biorreatores de membrana (MBRs). Os grânulos são formados através da auto-imobilização dos microrganismos na ausência de um meio suporte sólido. Por este motivo, pode-se concluir que os reatores anaeróbios com lodo granular são os mais favoráveis de todas as biotecnologias de auto-imobilização existentes, considerando que todo o volume do reator será efetivamente preenchido por biomassa (Liu et al., 2002).

Diversos estudos utilizaram cátions polivalentes para a granulação de lodo anaeróbio. Além disso, um estudo recente comprovou o beneficiamento da formação de grânulos com o aumento da salinidade (Sudmalis et al., 2018). Assim, o primeiro objetivo deste trabalho foi 


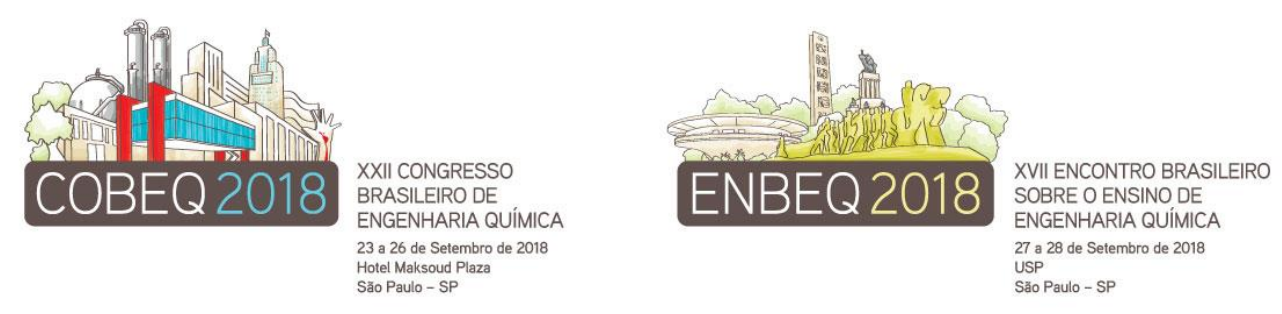

avaliar o comportamento de diferentes agentes na granulação de um lodo floculento anaeróbio em reatores em batelada sequencial. Em seguida, buscou-se avaliar a influência da adição desse agente continuamente ou intermitentemente sobre a granulação do lodo e, por fim avaliar o efeito da adição de fármacos na granulação do lodo.

\section{MATERIAL E MÉTODOS}

Inicialmente, três reatores anaeróbios em batelada sequencial (R1, R2 e R3), com volume de $1 \mathrm{~L}$ cada, foram alimentados em ciclos de 8 e 16 horas. Todos os reatores foram inoculados com $5 \mathrm{~g} / \mathrm{L}$ de lodo de um UASB de uma estação de tratamento de esgoto da cidade de Belo Horizonte e alimentados com esgoto sintético, cuja composição foi adaptada de Gomes et al. (2015). R1 foi o reator controle, R2 foi alimentado com maior concentração de $\mathrm{NaCl}$ (12 g/L), essa concentração foi estabelecida de acordo com estudos de Sudmalis et al. (2018); e R3 foi alimentado com excesso de $\mathrm{CaCl}_{2}(250 \mathrm{mg} / \mathrm{L})$, concentração selecionada de acordo com estudos de Yu et al. (2001). No final de cada ciclo, 0,5 L de esgoto tratado era descarregado e 0,5 L de esgoto sintético fresco era adicionado. Após cada alimentação, uma pequena agitação era realizada em cada reator, para garantir que toda a biomassa estivesse em contato com o substrato.

Realizados esses testes, em um segundo momento, operou-se sistemas similares, sendo um deles com adição de fármacos (R6) para a verificação da influência desses sobre o crescimento do grânulo. E além disso, avaliou-se o efeito da adição contínua e intermitente do melhor agente para o desenvolvimento dos grânulos, reatores R4 e R5, respectivamente. Destacando que o melhor agente foi avaliado nos primeiros testes.

As medidas de tamanho de partícula foram realizadas em um analisador de distribuição de tamanho de partículas por dispersão a laser (modelo LA-950, Horiba) e análises de monitoramento foram realizadas periodicamente, como carbono orgânico total (COT), ácidos graxos voláteis (VFA) e $\mathrm{pH}$. As análises estatísticas foram realizadas no programa Statistica 10.

\section{RESULTADOS E DISCUSSÃO}

De acordo com a Figura 1, durante 45 dias de monitoramento, o reator R3 foi o que apresentou o maior tamanho médio de grânulo quando comparado aos demais (R1 e R2).

Como mostrado na Tabela 1, o reator R3 também foi o que apresentou as melhores condições de operação, com maior remoção de COT e menor concentração de AGV no efluente. A menor concentração de ácidos no efluente do reator indica o consumo desses ácidos pela ocorrência de metanogênese. Testes não paramétricos de comparações múltiplas (Kruskal Wallis) foram aplicados com o intuito de evidenciar diferenças nos parâmetros monitorados e os resultados indicaram diferenças significativas entre o reator R3 e os demais reatores a um nível de significância de $5 \%$. 


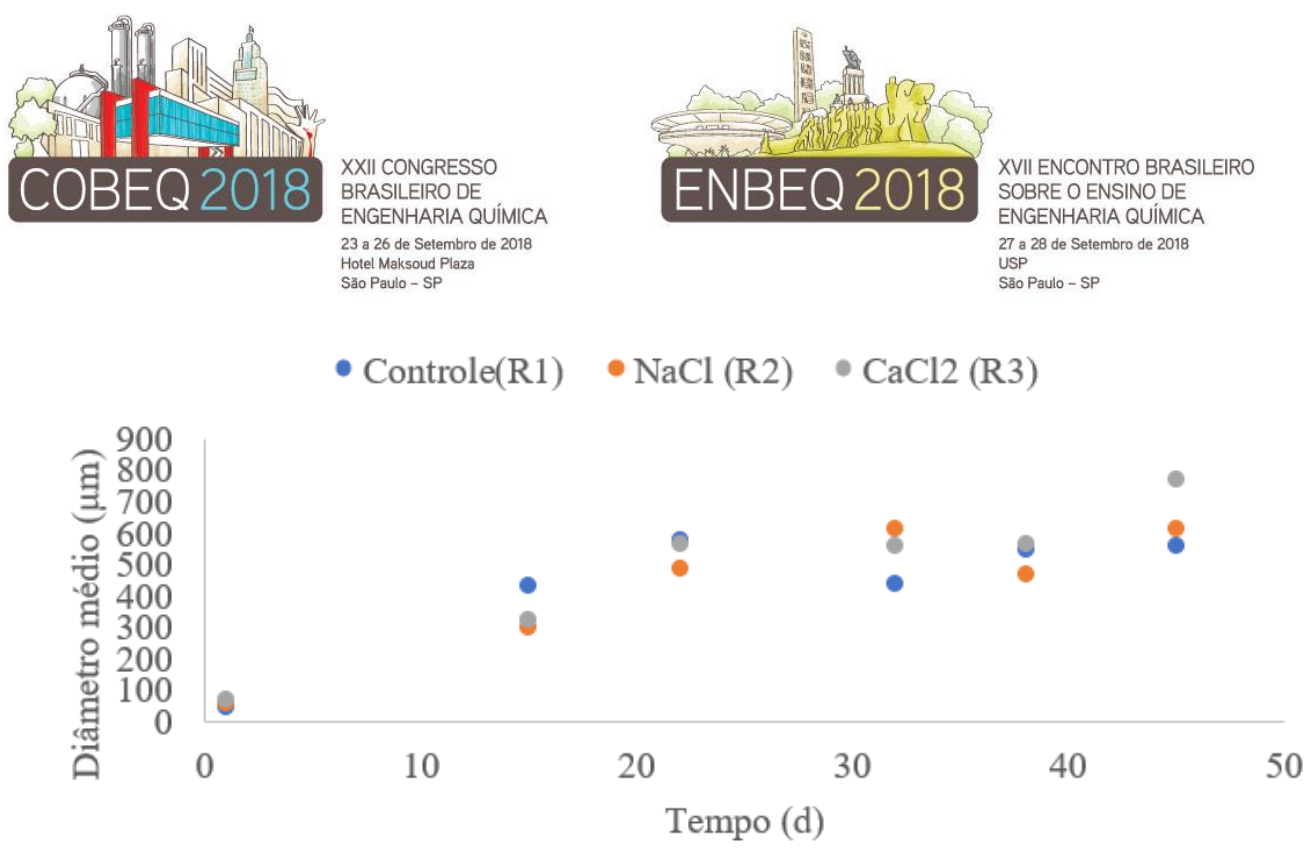

Figura 1 - Tamanho médio dos grânulos de cada reator anaeróbio.

Tabela 1 - Resultado do monitoramento de cada reator anaeróbio de batelada sequencial

\begin{tabular}{|c|c|c|c|}
\hline Parâmetros monitorados & Controle (R1) & $\mathrm{CaCl}_{2}(\mathrm{R} 3)$ & $\mathrm{NaCl}(\mathrm{R} 2)$ \\
\hline Remoção de COT (\%) & $56,85 \pm 10,92$ & $65,55 \pm 9,05$ & $37,82 \pm 7,68$ \\
\hline$p H$ & & & \\
\hline Afluente & $6,64 \pm 0,23$ & $6,62 \pm 0,11$ & $6,45 \pm 0,13$ \\
\hline Efluente & $6,60 \pm 0,25$ & $6,77 \pm 0,25$ & $6,57 \pm 0,13$ \\
\hline \multicolumn{4}{|l|}{$A G V(m g H A c / L)$} \\
\hline Afluente & $52,88 \pm 19,98$ & $53,1 \pm 21,45$ & $108,94 \pm 116,41$ \\
\hline Efluente & $108,31 \pm 33,67$ & $48.16 \pm 42.00$ & $93,71 \pm 31,88$ \\
\hline
\end{tabular}

Diante desses resultados, os novos testes que vêm sendo realizados, mesmo com pouco tempo de operação, evidenciam que a alimentação intermitente com o excesso de $\mathrm{CaCl}_{2} \mathrm{faz}$ com que o tamanho médio dos grânulos oscile (Figura 2). A alimentação intermitente, pode ser entendida como um choque de $\mathrm{CaCl}_{2}$, em uma semana o reator é alimentado com esgoto sintético e na outra semana com esgoto sintético acrescido de cloreto de cálcio $(250 \mathrm{mg} / \mathrm{L})$.

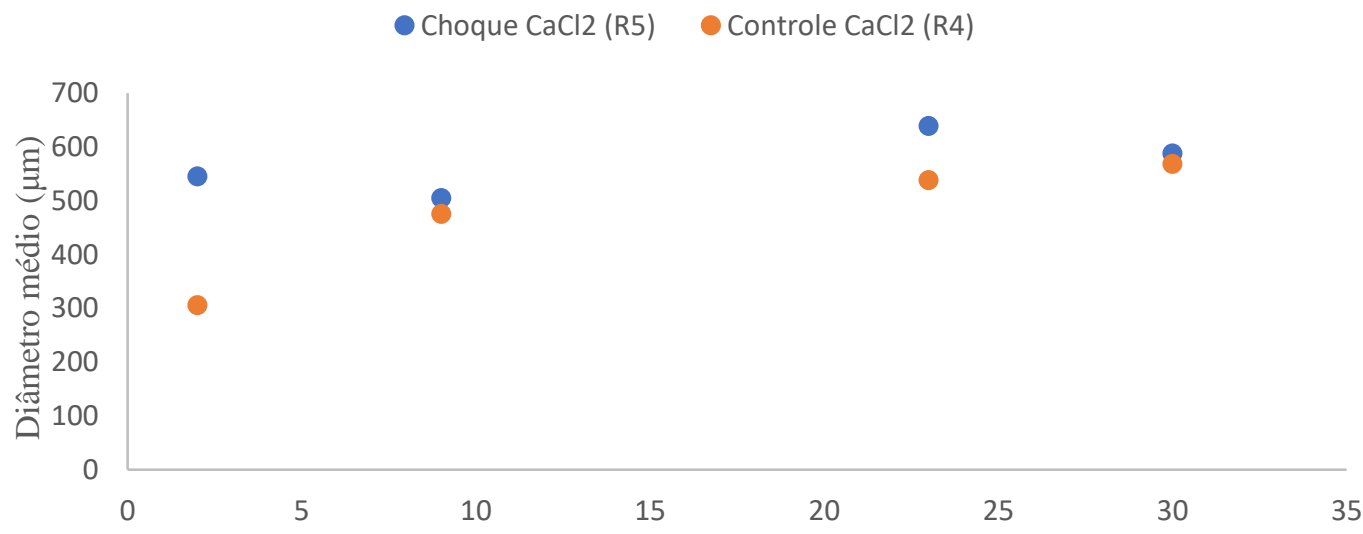

Figura 2 - Diâmetro médio dos grânulos dos reatores R4 e R5. 


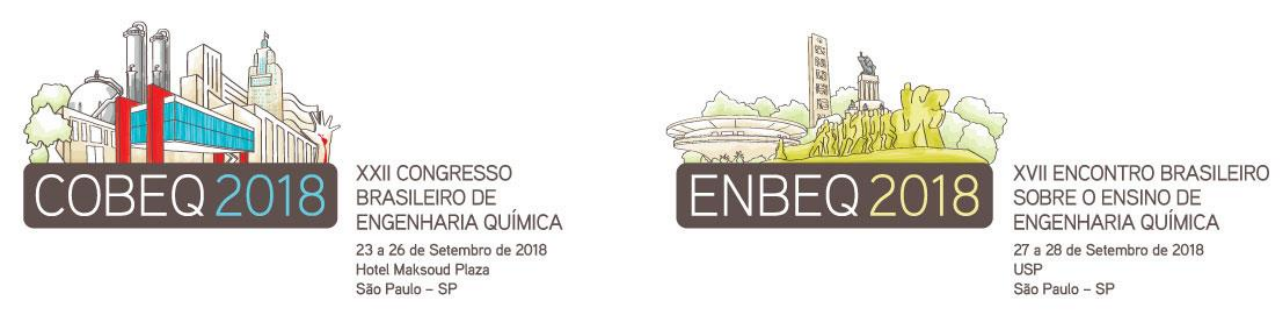

Quando os fármacos foram adicionados na alimentação ficou evidente a influência no decréscimo do tamanho médio dos grânulos (Figura 3).

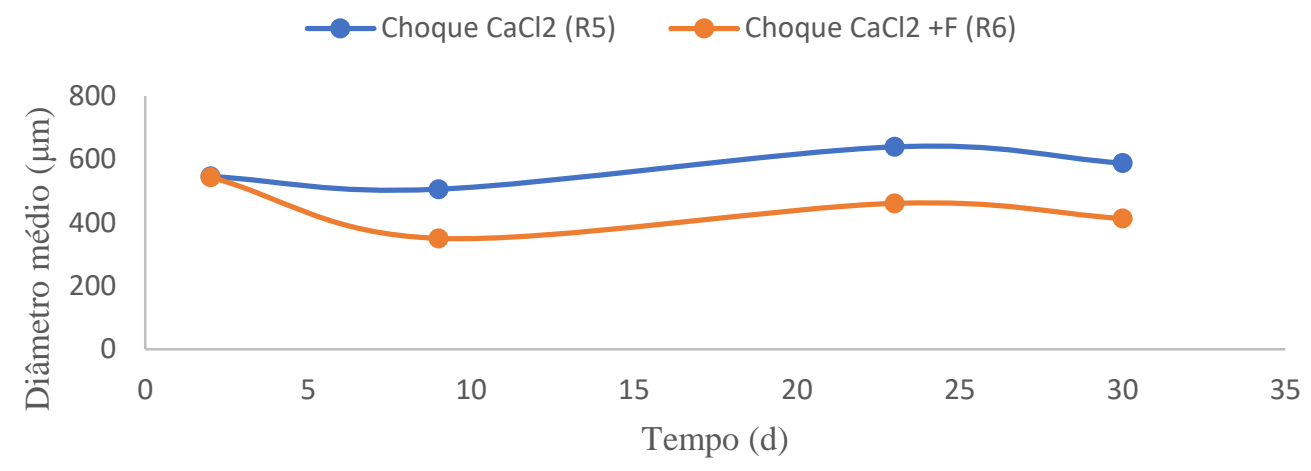

Figura 3 - Diâmetro médio dos grânulos dos reatores R5 e R6.

\section{CONCLUSÕES}

Esse estudo evidencia o uso de $\mathrm{CaCl}_{2}$ como agente para a granulação de lodo anaeróbio. $\mathrm{E}$, além disso, vem sendo demonstrado que a presença de fármacos na alimentação do reator influencia no crescimento dos grânulos e que o tamanho médio dos grânulos oscila quando a adição do $\mathrm{CaCl}_{2}$ é realizada de modo intermitente.

\section{REFERÊNCIAS}

GOMES PCL, TOMITA IN, SANTOS-NETO AJ, ZAIAT M. Rapid determination of 12 antibiotics and caffeine in sewage and bioreactor effluent by online column-switching liquid chromatography/tandem mass spectrometry. Anal Bioanal Chem, v. 407(29), p.8787-801, 2015.

LIU Y, XU HL, SHOW K-Y, TAY J-H. Anaerobic granulation technology for wastewater treatment. World J Microbiol Biotechnol, v. 18 (2), p. 99-113, 2002.

LIU Y-Q, WU W-W, TAY J-H, WANG J-L. Starvation is not a Prerequisite for the Formation of Aerobic Granules. Appl Microbiol Biotechnol, v. 76, p. 211-216, 2007.

RATUSZNEI SM, RODRIGUES JAD, CAMARGO EFM, ZAIAT M, BORZANI W. Feasibility of a stirred anaerobic sequencing batch reactor containing immobilized biomass for wastewater treatment. Bioresour Technol, v. 75 (2), p. 127-132, 2000.

SUDMALIS D, GAGLIANO MC, PEI R, GROLLE K, PLUGGE CM, RIJNAARTS HHM, ZEEMAN G, TEMMINK H. Fast anaerobic sludge granulation at elevated salinity. Water Res, v. 128, p. 293-303, 2018.

YU HQ, TAY JH, FANG HHP. The roles of calcium in sludge granulation during UASB reactor start-up. Water Res, v. 35 (4), p. 1052-1060, 2001. 